\title{
Perceptions of a night float system for intern doctors in an internal medicine program: an Asian perspective
}

\author{
Benjamin Yong-0iang Tan', Nicholas Jinghao Ngiam¹, Zi Yun Chang', Sandra Ming Yien Tan', Xiayan Shen', \\ Shao Feng Mok', Srinivas Subramanian', Shirley Beng Suat ${ }^{1}{ }^{2}{ }^{2}$ and Adrian Chin-Leong Kee ${ }^{1}$ \\ Departments of ${ }^{1}$ Medicine and ${ }^{2}$ Emergency Medicine, National University Health System, Singapore
}

Long duty hours have been associated with significant medical errors, adverse events, and physician "burn-out". An innovative night float (NF) system has been implemented in our internal medicine program to reduce the negative effects of long duty hours associated with conventional full-call systems. However, concerns remain if this would result in inadequate training for interns. We developed a structured questionnaire to assess junior doctors' perceptions of the NF system compared to full calls, in areas of patient safety, medical training, and well-being. Ninety-seven (71\%) of the 137 doctors polled responded. Ninety-one (94\%) felt the NF system was superior to the full call system. A strong majority felt NF was beneficial for patient safety compared to full call $(94 \%$ vs. $2 \%$, $p<0.001)$. The NF system was also perceived to reduce medical errors $(94 \%$ vs. $2 \%, p<0.001)$ and reduce physician "burn-out" ( $95 \%$ vs. $5 \%, p<0.001)$. Beyond being a practical solution to duty-hour limitations, there was a significant perceived benefit of the NF system compared to the full call in terms of overall satisfaction, patient safety, reducing medical errors and physician "burn-out".

Key Words: After-hours care, Patient safety, Medical education

\section{Introduction}

There is increasing evidence that sleep deprivation and long duty hours have been associated with significant medical errors [1], adverse events [2], and physician burnout [3]. The Accreditation Council for Graduate Medical Education (ACGME) has provided guidelines and regulations for mandated working hours for residents [4]. The structure and design of the after-hours "on-call" system among junior doctors have hence become an important concern for many residency programmes across the world.
Night float (NF) systems had been introduced in many residency programmes and institutions worldwide to address the ACGME regulatory requirements [5]. The system introduces a dedicated team of junior doctors who takes over the care of patients from the day team for consecutive nights in a week. The day team would resume care of patients the following day and hence eliminates the need for a prolonged post-call working day. Such a NF system has been applied to a range of specialties with success, including internal medicine and obstetrics and gynaecology [6-8].

While the NF system is a practical solution, it has also faced challenges and resistance due to concerns of
Received: April 23, 2019 • Revised: June 14, 2019 • Accepted: June 24, 2019 Corresponding Author: Benjamin Yong-Qiang Tan (https://orcid.org/0000-0003-1824-9077) Division of Neurology, Department of Medicine, National University Health System, 1E Kent Ridge Rd, NUHS Tower Block, Level 10, Singapore 119228

Tel: +65.6779.5555 Fax: +65.6734.1641 email: Benjamin_yq TAN@nuhs.edu.sg

*Presentation of this abstract was made during the proceedings of the Association for Medical Education in Europe (AMEE) 2018 in Basel, Switzerland.
Korean J Med Educ 2019 Sep; 31(3): 271-276.

https://doi.org/10.3946/kjme.2019.137

eISSN: 2005-7288

(C) The Korean Society of Medical Education. All rights reserved. This is an open-access article distributed under the terms of the Creative Commons Attribution Non-Commercial License (http:// creativecommons.org/licenses/by-nc/3.0/), which permits unrestricted non-commercial use, distribution, and reproduction in any medium, provided the original work is properly cited. 
inadequate teaching and training opportunities $[9,10]$ as well as worries over compromised patient safety, lack of care continuity, and increased medical errors [11-13] related to frequent need for handovers between the day and night team. Overall, in some institutions, these changes led to residents and junior doctors seeing their NF rotation as more of a "service" rather than part of their learning and training [14]. This paradoxically results in adverse effects on physician satisfaction.

Traditionally, National University Health System, Singapore operated on a "full-call" system, which involved our junior doctors working for more than 24 hours at a time without rest. In conjunct with the ACGME International (ACGME-I) accreditation, our institution was the first in the country to introduce the NF system for all post-graduate year one interns or residents in place of a full-call system in the department of medicine [8]. As these freshly-graduated doctors would be the most susceptible to the effects of physician fatigue, and for whom strong medical training would be critical and foundational to learning, we sought to evaluate the perceived effects of having a NF system in this population. We investigated the perceptions of the NF system implemented in a tertiary institution in Singapore, amongst junior doctors who had rotated through our department of medicine as part of their intern rotation.

\section{Methods}

Based on our literature review using PubMed, we found that the major domains concerning NF and interns fell into the domains of (1) patient safety; (2) medical training and education; and (3) physician well-being. We then worked together with core faculty in our institution to develop a questionnaire to assess these domains. The questionnaire included both positive and negative items, and also employing a 5-point Likert scale ranging from "strongly-agree" to "strongly-disagree". For questions involving the 5-point Likert scale, a score of 4 or greater was considered a positive response. With the finalized questionnaire, all junior doctors who were currently posted to the department of medicine and had personally undergone the NF system during their intern rotations were anonymously surveyed.

We employed chi-square tests for proportions (or Fisher's exact test where appropriate) to compare our populations' perceptions towards NF compared to fullcall in the specific domains studied. All data analysis was carried out using with IBM SPSS for Windows ver. 20.0 (IBM Corp., Armonk, USA). A p-value of less than 0.05 was considered to be statistically significant in this study. The study was deemed to be a Quality Improvement type study and was approved and given an exempt from review by our Institutional Review Board. Informed consent was obtained from all individual participants included in the study.

\section{Results}

The questionnaire was distributed to 137 residents and the response rate was $71 \%$ (97 of 137). Our respondents ranged from 23 to 30 years of age (median age, 26 years), and were all junior doctors between their first to fifth post-graduate year of training. All 97 respondents had experienced NF in the department of medicine of our institution in their intern rotation.

Regardless of age, gender, or year-of-training, a majority of junior doctors 91 (94\%) felt that the NF system was superior to full call, and $83(86 \%)$ felt that the presence of the NF system would influence their choice of training institution for residency. The junior 
Table 1. Junior Doctors' Perceptions on Night-Float Compared to Full-Call Systems $(n=97)$

\begin{tabular}{lccc}
\hline \multicolumn{1}{c}{ Domain } & Night float & Full call & p-value \\
\hline Beneficial for patient safety & $91(94)$ & $1(2)$ & $<0.001$ \\
Reduces medical errors & $91(94)$ & $1(2)$ & $<0.001$ \\
Reduces physician burnout & $92(95)$ & $5(5)$ & $<0.001$ \\
Builds teamwork & $91(94)$ & $6(6)$ & $<0.001$ \\
Produces less competent trainees & $5(5)$ & $1(2)$ & 0.211 \\
\hline
\end{tabular}

Data are presented as number $(\%)$.

${ }^{\text {al }}$ By chi-square test.

Table 2. Subgroup Analysis of Perceptions of Junior Doctors Who Had Undergone Both Night-Float and Full-Call during Their Post-graduate Year One Rotation $(n=44)$

\begin{tabular}{lccc}
\hline \multicolumn{1}{c}{ Domain } & Night float & Full call & p-value \\
\hline Beneficial for patient safety & $43(98)$ & 0 & - \\
Reduces medical errors & $43(98)$ & 0 & - \\
Reduces physician burnout & $43(98)$ & $1(2)$ & $<0.001$ \\
Builds teamwork & $42(95)$ & $2(5)$ & $<0.001$ \\
Produces less competent trainees & $2(5)$ & 0 & - \\
\hline
\end{tabular}

Data are presented as number (\%).

a) By chi-square test.

doctors perceived the NF system to be superior to full call in terms of patient safety and physician well-being, and did not compromise medical training (Table 1). A vast majority of junior doctors felt that the NF system was beneficial for patient safety compared to full call (94\% versus $2 \%, \mathrm{p}<0.001)$ and also reduced medical errors $(94 \%$ versus $2 \%, \mathrm{p}<0.001)$. Similarly the NF system was perceived to reduce physician "burn-out" compared to full call (95\% versus $5 \%, \mathrm{p}<0.001$ ). Only five junior doctors (5\%) felt the NF system was less adequate in producing competent trainees.

Forty-four respondents (45\%) had experienced both the NF system in our institution and full-call system in other hospitals and departments in their intern rotations. Subgroup analysis of these 44 junior doctors showed that all but one ( $n=43,98 \%)$ favoured the NF system in terms of patient safety, reducing medical errors and reducing physician burn-out (Table 2). Within this group, 39 (88\%) felt they were more likely to make mistakes after a full call, and only $7(16 \%)$ felt confident to function safely after a full call.

\section{Discussion}

Our study focused on interns who were fresh out of medical school, believing that they were the most vulnerable group of junior doctors to changes in medical training and programme structure. Although the NF system is ubiquitous in the Western setting, it is less prominent both locally and in the region, perhaps influenced by traditional cultural norms of long working hours [15]. The implementation and structure of the NF system took into account the feedback and concerns of the junior doctors, an approach that had been described to be effective [16]. The effect of a NF system to fulfil the ACGME-I duty-hour restrictions was therefore important to assess in this relatively inexperienced group, in the domains of patient care, medical training and physician well-being.

Almost unanimously, the doctors in our institution believed that the NF system was beneficial for patient care and safety over the full-call system. This sentiment 
was similar to previous studies in the Western setting [17]. The primary reason for this was the fact that more "well-rested" physicians were more conscientious and thus made "better clinical judgments" and expressed greater empathy and care towards patients. Junior doctors expressed that during a busy full call, it was not uncommon to have a "survival-mode" mentality, where the primary objective was to seek rest. The physician may then become too preoccupied with his own fatigue and needs, at the expense of dismissing patients' symptoms and compromising patient care. While our study convincingly demonstrated that our junior doctors found the NF system provided them with better rest and psychological well-being, other previous studies in the Western context have had more attenuated findings $[6,18]$. While there are subtle differences in the NF systems, the greater perceived benefit of our NF system may be the result of the junior doctors' input with regards to the design of the float system.

There are several important concerns with regards to the NF system. Firstly, it was thought that continuity of patient care would be interrupted with the NF system as there was a constant changeover of junior doctors responsible for individual patients. However, our study found that continuity of care was not perceived to pose a significant issue amongst the junior doctors we surveyed, which was contrary to studies carried out in other institutions $[19,20]$. Perhaps a robust handover system employed by our institution which relied both on verbal (over-the-phone) and written (electronicallydocumented) instructions had resulted in better continuity of care despite the need for transitioning care to another team at night. Although not examined in our study, it was further demonstrated that most nurses surveyed also felt that the NF system was safer, with residents making fewer mistakes and being easier to work with [21,22].
A second major criticism of the NF system was the potential compromise in the quality of medical training and education. This was due to the reduced hours and exposure that a junior doctor would have to experience. Furthermore, most didactic teaching sessions would be conducted during office-hours, and while on NF duty, the junior doctor would not be able to attend teaching sessions for that week. These important considerations were taken into account during the design of the NF system to minimize interruption to the teaching syllabus for the junior doctors involved. Teaching materials were freely made available to junior doctors for learning at their own time.

Instead of being compromised, most of our junior doctors felt that the NF system was an improvement to their medical training and education. The shortened work shifts in a NF system introduces the opportunity for more "reflection-on-action" (reading, debriefing, self-assessment, and so forth) in between shifts, thus potentially enriching the educational experience [23]. The perception towards NF with regards to education in our institution largely remained positive, which was in stark contrast to prior studies where some residents perceived the NF to be a "service rotation" with minimal learning value $[24,25]$. Instead, many of our junior doctors felt that NF rotation exposed them to a vast range of cases and clinical scenarios which they might not have the chance to encounter in their regular rotations. Similarly, a well-rested physician with optimal mental and physical well-being formed the optimal substrate for "critical thinking" and "practice-based learning" even while on- call. Many also commented that they benefited from the supervision and guidance of more senior members of the NF team. Such mentorship was perceived to be more difficult in a full-call setting, where both the senior and junior doctors were struggling to cope with their respective workloads, with inadequate 
rest.

There was better perceived physician well-being and satisfaction with the NF system. There were lower levels of fatigue and burn-out, better perceived delivery of patient care, and no compromise in training opportunities. Beyond those discussed earlier, another common reason cited was the sense of teamwork fostered during NF. The presence of a fixed "night-float team" which cared for patients on consecutive nights for a week led to a strong sense of camaraderie which carried on to subsequent postings as well.

\section{Limitations}

We acknowledge that our study remained moderatelysized and had a modest response rate. Inherent bias may be present where junior doctors who were less in favour of the NF system may have been less willing to respond to the questionnaire. Nevertheless, the findings of our respondents convincingly demonstrate the perceived superiority of the NF system compared to the full call. Our questionnaire was designed as part of quality improvement and assurance; and future expansion of the study with an added qualitative assessment will add to reliability of the data.

\section{Conclusions}

The NF system for interns was well-received in our institution, and led to increased overall perceived satisfaction. Junior doctors in their first year of training believed it was able to reduce medical errors and improve physician well-being, and did not compromise on the quality of their medical training.

\section{ORCID:}

Benjamin Yong-Qiang Tan: https://orcid.org/0000-0003-1824-9077;

Nicholas Jinghao Ngiam: https://orcid.org/0000-0002-3339-7281;
Zi Yun Chang: https://orcid.org/0000-0002-4719-8048;

Sandra Ming Yien Tan: https://orcid.org/0000-0001-9888-1018;

Xiayan Shen: https://orcid.org/0000-0001-7248-0179;

Shao Feng Mok: https://orcid.org/0000-0002-8826-8241;

Srinivas Subramanian: https://orcid.org/0000-0002-2855-0819;

Shirley Beng Suat Ooi: https://orcid.org/0000-0002-8661-7225;

Adrian Chin-Leong Kee: https://orcid.org/0000-0001-6531-2847

Acknowledgements: The authors would like to thank professor Dan Yock Young and the staff of the Department of Medicine, National University Hospital, for supporting this study.

Funding: No funding was received for this research.

Conflicts of interest: No potential conflict of interest relevant to this article was reported.

Author contributions: Tan BY, Mok SF, Srinivas S, Ooi $\mathrm{SB}$, and Kee AC were involved in the conception of the work, critical revision of the article, and final approval of the version to be published. Ngiam NJ, Chang ZY, Tan SM, and Shen XY were involved in data collection, data analysis and interpretation, and drafting the article.

\section{References}

1. Barger LK, Ayas NT, Cade BE, et al. Impact of extendedduration shifts on medical errors, adverse events, and attentional failures. PLoS Med. 2006;3(12):e487.

2. Lockley SW, Cronin JW, Evans EE, et al. Effect of reducing interns' weekly work hours on sleep and attentional failures. N Engl J Med. 2004;351(18):1829-1837.

3. Shanafelt TD, Bradley KA, Wipf JE, Back AL. Burnout and self-reported patient care in an internal medicine residency program. Ann Intern Med. 2002;136(5):358367.

4. Accreditation Council for Graduate Medical Education. ACGME approves new proposed common requirements for resident duty hours. Washington DC, USA: Accredit- 
ation Council for Graduate Medical Education; 2002.

5. Foster HW Jr, Seltzer VL. Accommodating to restrictions on residents' working hours. Acad Med. 1991;66(2): 94-97.

6. Trontell MC, Carson JL, Taragin MI, Duff A. The impact of the night float system on internal medicine residency programs. J Gen Intern Med. 1991;6(5):445-449.

7. Seltzer V, Foster HW Jr, Gordon M. Resident scheduling: night float programs. Obstet Gynecol. 1991;77(6):940943.

8. Kee CL, Goh WP, Yap ES, Chan YC. Impact of a newly introduced medical officer night-float on-call system in a medical department in Singapore. Singapore Med J. $2011 ; 52(1): 60-62$.

9. Wood VC, Markert RJ, McGlynn TJ. Internal medicine residents' perceptions of the balance between service and education in their night-call activities. Acad Med. 1993; 68(8):640-642.

10. Yedidia MJ, Lipkin M Jr, Schwartz MD, Hirschkorn C. Doctors as workers: work-hour regulations and interns' perceptions of responsibility, quality of care, and training. J Gen Intern Med. 1993;8(8):429-435.

11. Gottlieb DJ, Parenti CM, Peterson CA, Lofgren RP. Effect of a change in house staff work schedule on resource utilization and patient care. Arch Intern Med. 1991;151(10):2065-2070.

12. Petersen LA, Brennan TA, O’Neil AC, Cook EF, Lee TH. Does housestaff discontinuity of care increase the risk for preventable adverse events? Ann Intern Med. 1994; $121(11): 866-872$

13. Griffith $\mathrm{CH}$ 3rd, Rich EC, Hillson SD, Wilson JF. Internal medicine residency training and outcomes. J Gen Intern Med. 1997;12(6):390-396.

14. Wartman SA, O'Sullivan PS, Cyr MG. The service/ education conflict in residency programs: a model for resolution. J Gen Intern Med. 1990;5(1 Suppl):S59-S69.

15. Oh SH, Kim JS, Lee PS. A survey on training and work- ing conditions of residents in 2015. J Korean Med Assoc. 2015;58(12):1179-1189.

16. Sadowski BW, Medina HA, Hartzell JD, Shimeall WT. Nighthawk: making night float education and patient safety soar. J Grad Med Educ. 2017;9(6):755-758.

17. Rosenberg M, McNulty D. Beyond night float?: the impact of call structure on internal medicine residents. J Gen Intern Med. 1995;10(2):95-98.

18. Gottlieb DJ, Peterson CA, Parenti CM, Lofgren RP. Effects of a night float system on housestaff neuropsychologic function. J Gen Intern Med. 1993;8(3):146-148.

19. Lofgren RP, Gottlieb D, Williams RA, Rich EC. Post-call transfer of resident responsibility: its effect on patient care. J Gen Intern Med. 1990;5(6):501-505.

20. Laine C, Goldman L, Soukup JR, Hayes JG. The impact of a regulation restricting medical house staff working hours on the quality of patient care. JAMA. 1993;269(3): $374-378$

21. Buff DD, Shabti R. The night float system of resident on call: what do the nurses think? J Gen Intern Med. 1995; $10(7): 400-402$.

22. Akl EA, Bais A, Rich E, Izzo J, Grant BJ, Schünemann HJ. Brief report: internal medicine residents', attendings', and nurses' perceptions of the night float system. J Gen Intern Med. 2006;21(5):494-497.

23. Moeller A, Webber J, Epstein I. Resident duty hour modification affects perceptions in medical education, general wellness, and ability to provide patient care. BMC Med Educ. 2016;16:175.

24. Lieu TA, Forrest CB, Blum NJ, Cornfeld D, Polin RA Effects of a night-float system on resident activities and parent satisfaction. Am J Dis Child. 1992;146(3):307310.

25. Lurie N, Rank B, Parenti C, Woolley T, Snoke W. How do house officers spend their nights?: a time study of internal medicine house staff on call. N Engl J Med. 1989;320(25):1673-1677. 